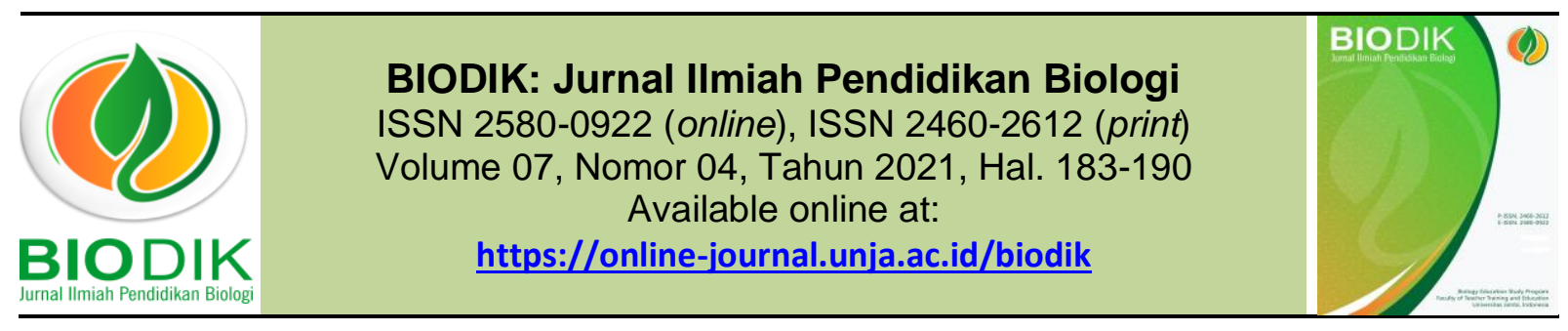

Research Article

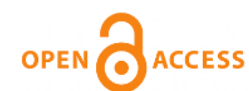

\title{
Analisis Desain Kegiatan Laboratorium Pertumbuhan dan Perkembangan Tumbuhan
}

\section{(Design Analysis of Plant Growth and Development Laboratory Activities)}

Trisna Dewi*, Sri Anggraeni, Bambang Supriatno

Program Studi Pendidikan Biologi, Sekolah Pascasarjana, Universitas Pendidikan Indonesia Jalan Dr. Setiabudi, No.299, Cidadap, Isola, Sukasari, Kota Bandung 40154, Indonesia

*Corresponding Athorr: Trisnadewi324@gmail.com

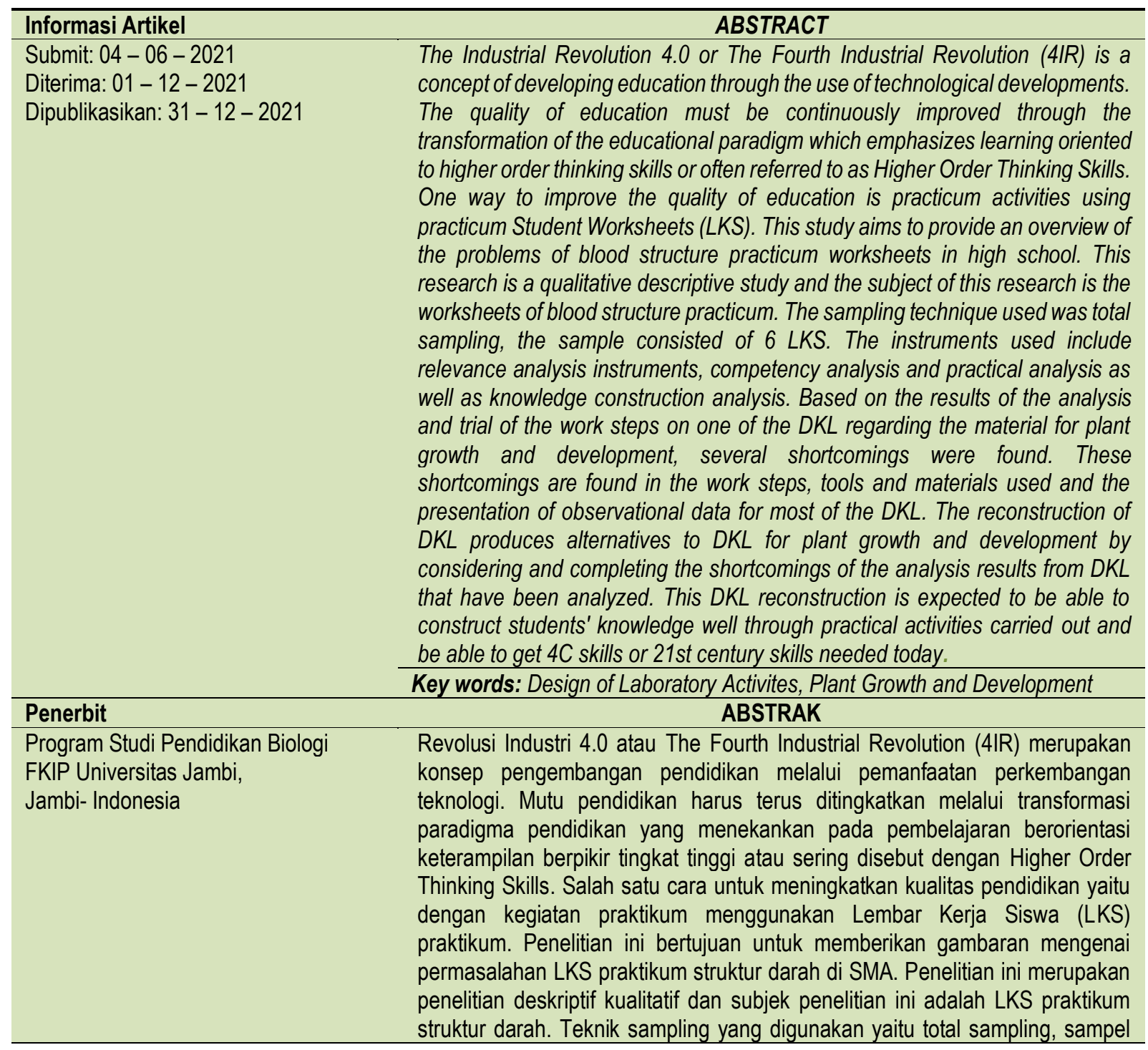


terdiri dari 6 LKS. Instrumen yang digunakan meliputi instrumen analisis relevansi, analisis kompetensi dan analisis praktikal serta analisis konstruksi pengetahuan. Berdasarkan hasil analisis dan uji coba Langkah kerja terhadap salah satu DKL. mengenai materi pertumbuhan dan perkembangan tumbuhan ditemukan beberapa kekurangan. Kekurangan tersebut didapatkann pada langkah kerja, alat dan bahan yang digunakan serta penyajian data pengamatan Sebagian besar DKL. Rekontruksi DKL menghasilkan alternatif DKL pertumbuhan dan perkembangan tumbuhan dengan mempertimbangkan dan melengkapi kekurangan hasil analisis dari DKL yang sudah di analisis. Rekontruksi DKL ini diharapkan mampu mengkontruksi pengetahuan peserta didik dengan baik melalui kegiatan praktikum yang dilakukan serta mampu mendapatkan keterampilan $4 \mathrm{C}$ atau keterampilan abad 21 yang dibutuhkan saat ini.

Kata kunci: Desain Kegiatan Laboratorium, Pertumbuhan dan perkembangan tumbahan

This BIODIK : Jurnal IImiah Pendidikan Biologi is licensed under a CC BY-NC-SA (Creative Commons Attribution-ShareAlike 4.0 International License)

\section{PENDAHULUAN}

Revolusi Industri 4.0 atau The Fourth Industrial Revolution (4IR) merupakan konsep pengembangan pendidikan melalui pemanfaatan perkembangan teknologi. Mutu pendidikan harus terus ditingkatkan melalui transformasi paradigma pendidikan yang menekankan pada pembelajaran berorientasi keterampilan berpikir tingkat tinggi atau sering disebut dengan Higher Order Thinking Skills (Muhali, 2018). Hal ini memberikan konsekuensi dan dampak yang nyata pada bidang pendidikan sains untuk memenuhi kebutuhan yang ada di masa depan melalui pemanfaatan teknologi. Pendidikan sains memiliki peranan dalam menghasilkan sumber daya manusia yang inovatif dan memiliki kompetensi unggul baik secara soft skill maupun hard skill sehingga dapat disejajarkan bahkan mampu bersaing dengan sumber daya manusia dari negara lain untuk menghadapi berbagai isu-isu global (Yuliati, 2019).

Salah satu cara dalam meningkatkan kualitas pendidikan yaitu melalui pembelajaran prosedural. Pengetahuan prosedural ini dapat diperoleh siswa melalui kegiatan praktikum. Kegiatan praktikum yaitu kegiatan di mana siswa dapat mengamati suatu objek atau fenomena secara nyata (Abraham, 2008). Praktikum merupakan strategi yang mengarahkan siswa untuk menemukan suatu pengetahuan dari konsep-konsep yang diperoleh dari pengalaman langsung dalam mengamati suatu objek atau fenomena (Hamidah, 2016). Guru biologi tentu sangat berperan dalam pembelajaran biologi karena dengan adanya pengetahuan guru tersebut ddalam melakukan kegiatan praktikum dapat berpengaruh kuat pada keterlibatan aktif siswa pada pembelajaran biologi (Turner, 2017). Sehingga guru biologi harus terampil dan kompeten dalam merancang, mempersiapkan dan melaksanakan pembelajaran biologi khususnya kegiatan praktikum (Fadzil \& Saat, 2020).

Lembar Kerja Siswa (LKS) merupakan salah satu sumber belajar yang dapat dikembangkan oleh guru sebagai fasilitator dalam kegiatan pembelajaran. LKS yang disusun dapat dirancang dan dikembangkan sesuai dengan kondisi dan situasi kegiatan pembelajaran yang akan dihadapi. LKS juga merupakan media pembelajaran, karena dapat digunakan secara bersama dengan sumber belajar atau media pembelajaran yang lain. LKS menjadi sumber belajar dan media pembelajaran tergantung pada kegiatan pembelajaran yang dirancang. Keberadaan LKS memberi pengaruh yang cukup besar dalam 
proses belajar mengajar, sehingga penyusunan LKS harus memenuhi berbagai persyaratan yaitu syarat didaktik, syarat konstruksi, dan syarat Teknik. Agar LKS yang disusun dapat diukur kualitasnya, maka perlu diadakan penilaian oleh mereka yang dianggap berkompeten. Sedangkan penentuan kualitas LKS didasarkan pada asumsi standar ideal (kurva normal), yaitu membandingkan dengan skor ideal.

Permasalahan yang dipaparkan oleh (Supriatno, 2013) pun ditemukan oleh peneliti. Berdasarkan hasil analisis peneliti terhadap DKL tentang pertumbuhan dan perkembangan beberapa DKL tidak memiliki tujuan praktikum yang jelas, objek fenomena tidak sesuai, serta kegiatan praktikum yang tidak sesuai dengan teori prinsip maupun konsep. Mayoritas DKL tidak menginstruksikan siswa untuk mencatat fenomena apa saja yang ditemukan saat praktikum. Sehingga kegiatan praktikum hanya sebatas pada kegiatan mengamati bukan bagian dari kegiatan mengkontruksi pengetahuan. Hal ini jelas akan mempengaruhi penarikan kesimpulan yang dilakukan oleh siswa karena pada dasarkan kesimpulan yang didapatkan siswa harus sesuai dengan tujuan dan kegiatan praktikum yang dilakukan.

\section{METODE PENELITIAN}

Penelitian ini bertujuan untuk memberikan gambaran mengenai kualitas Desain Kegiatan Laboratorium (DKL) atau Lembar Kerja Peserta Didik (LKPD) pada materi pertumbuhan dan perkembang serta membuat rekonstruksi DKL untuk meningkatkan pemahaman peserta didik. Penelitian ini merupakan penelitian deskriptif karena penelitian ini menyelidiki kualitas hubungan, kegiatan, situasi atau bahan (Fraenkel, et al., 2012). Subjek penelitian ini adalah 6 unit DKL Perkembangan dan pertumbuhan kelas XII yang biasa digunakan di sekolah. Teknik sampling yang digunakan yaitu purposive sampling. Analisis yang dilakukan menggunakan rubrik penilaian LKPD mencakup empat aspek yaitu aspek relevansi, aspek kompetensi, aspek praktikal dan aspek konstruksi pengetahuan. Setiap aspek terdiri dari beberapa indikator. Beberapa indikator tersebut diadaptasi dari beberapa ahli, diantaranya Representasi data diadaptasi dari Fisher et al (1990), interpretasi yang diadaptasi dari Bertin (1983) dan Creswell, (2016), dan kemampuan berpikir yang diadaptasi dari Anderson \& Krathwohl, (2017) serta seluruh indikator pada aspek konstruksi pengetahuan diadaptasi dari Novak \& Gowin, (1984). Sedangkan indikator lainnya dikembangkan sendiri oleh penulis kemudian di validasi oleh dosen ahli hingga laik digunakan dalam penelitian. Adapun langkah menganalisis DKL terdiri dari sampling berbagai DKL, dilanjutkan dengan menganalisis DKL yang sudah di dapatkan berdasarkan intrumen yang telah ditentukan, kemudian salah satu DKL diuji coba, setelah itu di dianalisis kembali dan yang terakhir di rekonstruksi berdasarkan hasil analisis dan uji coba. Setelah didapatkan data, kemudian dianalisis secara kuantitatif.

\section{HASIL PENELITIAN DAN PEMBAHASAN}

\section{Hasil Analisis Desain Kegiatan Praktikum Pertumbuhan dan Perkembangan pada Tumbuhan}

Hasil temuan menunjukkan masih terdapat permasalahan pada LKS pertumbuhan dan perkembangan yang dianalisis. Permasalahan yang terjadi baik pada analisis relevansi, analisis Kompetensi, analisis praktikal dan analisis konstruksi pengetahuan dijelaskan sebagai berikut:

\section{Analisis Relevansi}

LKS praktikum yang dianalisis sudah menunjukkan komponen relevansi, tetapi skornya sangat bervariasi. Hampir seluruhnya LKS praktikum pertumbuhan dan perkembangan mencapai skor maksimal pada indikator KD dan tingkat kognitif. 
Tabel 1. Hasil analisis relevansi

\begin{tabular}{llllllll}
\hline No & Indikator & Lks 1 & Lks 2 & Lks 3 & Lks 4 & Lks 5 & Lks 6 \\
\hline 1 & $\begin{array}{l}\text { Relevansi kompetensi } \\
\text { dengan KD }\end{array}$ & 2 & 1 & 1 & 2 & 1 & 1 \\
\hline 2 & $\begin{array}{l}\text { Relevansi konten dengan } \\
\text { KD }\end{array}$ & 2 & 1 & 1 & 2 & 1 & 1 \\
\hline
\end{tabular}

Pada indikator relevansi kompetensi dengan KD hampir semua LKS memiliki Kompetensi yang dikembangkan pada kegiatan praktikum tidak memenuhi standar minimal KD. Jika kompetensi pada praktikum tidak sesuai dengan KD maka tuntutan KD tidak tercapai. Tetapi relevansi konten dengan KD pada kegiatan praktikum ini sudah memenuhi standar minimal KD.

\section{Analisis Kompetensi}

LKS praktikum yang dianalisis sudah menunjukkan komponen kompetensi, tetapi skornya sangat bervariasi. Hampir seluruhnya LKS praktikum pertumbuhan dan perkembangan mencapai skor maksimal pada indikator alat praktikum, bahan praktikum dan langkah-langkah praktikum.

Tabel. 2 Hasil analisis kompetensi

\begin{tabular}{llcccccc}
\hline No & Indikator & Lks 1 & Lks 2 & Lks 3 & Lks 4 & Lks 5 & Lks 6 \\
\hline 1 & Kemampuan observasi & 1 & 1 & 1 & 2 & 2 & 0 \\
\hline 2 & Transformasi data & 2 & 1 & 1 & 2 & 1 & 1 \\
\hline 3 & Interprestasi data & 2 & 0 & 1 & 2 & 1 & \\
\hline 4 & Level Kemampuan Kognitif & 2 & 1 & 1 & 1 & 1 & 1 \\
\hline
\end{tabular}

\section{Analisis Praktikal}

LKS praktikum yang dianalisis sudah menunjukkan komponen praktikal, tetapi skornya sangat bervariasi. Hampir seluruhnya LKS praktikum pertumbuhan dan perkembangan mencapai skor maksimal pada indikator alat praktikum, bahan praktikum dan langkah-langkah praktikum.

Tabel 3. Hasil analisis praktikal

\begin{tabular}{llllllll}
\hline No & Indikator & Lks 1 & Lks 2 & Lks 3 & Lks 4 & Lks 5 & Lks 6 \\
\hline 1 & $\begin{array}{l}\text { Kesesuaian alat praktikum } \\
\text { dengan standar sekolah }\end{array}$ & 2 & 1 & 1 & 2 & 1 & 1 \\
\hline 2 & $\begin{array}{l}\text { Kesesuaian bahan praktikum } \\
\text { dengan keperluan } \\
\text { kegiatan }\end{array}$ & 2 & 1 & 1 & 2 & 1 & 1 \\
\hline 3 & Struktur kerja praktikum & 4 & 3 & 3 & 4 & 4 & 4 \\
\hline
\end{tabular}


Berdasarkan hasil analisis menunjukkan bahwa secara keseluruhan 6 DKL tersebut sudah baik. Sebagian besar DKL menggunakan alat dan bahan yang sudah sesuai dengan standar lab dan mudah didapatkan, semua alat dan bahan pada DKL tersebut memiliki satuan yang jelas, prosedur kerja jelas dan tidak menimbulkan kesalahan namun semua DKL tidak dilengkapi gambar/ilustrasi/bagan.

\section{Hasil Analisis Konstruksi Pengetahuan}

LKS praktikum yang dianalisis sudah menunjukkan adanya komponen Diagram Vee, tetapi skornya sangat bervariasi. Hasil analisis konstruksi pengetahuan berdasarkan Diagram Vee pada LKS pertumbuhan dan perkembangan menunjukkan komponen yang umumnya sudah mencapai skor maksimal adalah komponen pertanyaan fokus. Sedangkan komponen yang lainnya seperti objek / peristiwa, konsep / prinsip/ teori dan klaim pengetahuan tidak mencapai skor maksimal. Hal ini disebabkan karena objek yang muncul sulit diidentifikasi sehingga berpengaruh terhadap konsep, prinsip, teori dan juga klaim pengetahuan.

\begin{tabular}{|c|c|c|c|c|c|c|c|}
\hline No & Indikator & Lks 1 & Lks 2 & Lks 3 & Lks 4 & Lks 5 & Lks 6 \\
\hline 1 & $\begin{array}{l}\text { Judul/tujuan/pertanyaan } \\
\text { fokus }\end{array}$ & 2 & 1 & 2 & 1 & 2 & 2 \\
\hline 2 & Objek fenomena & 2 & 1 & 1 & 2 & 1 & 2 \\
\hline 3 & Teori, prinsip, dan konsep & 2 & 2 & 1 & 2 & 1 & 2 \\
\hline 4 & $\begin{array}{l}\text { Perekaman \& transformasi } \\
\text { data }\end{array}$ & 2 & 1 & 1 & 2 & 1 & 2 \\
\hline 5 & Perolehan Pengetahuan & 2 & 1 & 1 & 2 & 2 & 1 \\
\hline
\end{tabular}

Indikator pertama yaitu pertanyaan fokus. Sebagian LKS sudah menunjukkan pertanyaan fokus dapat diidentifikasi meliputi bagian konseptual yang dapat digunakan serta mendukung peristiwa utama dan memperkuat objek. Indikator kedua yaitu objek fenomena pada LKS yang dianalisis tidak ada yang mencapai skor maksimal, tetapi sebagian dari LKS mencapai skor 1 yaitu peristiwa utama atau objek dapat diidentifikasi dan konsisten dengan pertanyaan fokus atau peristiwa dan objek dapat diidentifikasi tetapi tidak konsisten dengan pertanyaan focus.

Indikator ketiga yaitu konsep, prinsip, teori. Sebagian besar LKS mencapai skor 1 yaitu konsep yang dapat diidentifikasi sedikit tetapi tanpa prinsip-prinsip serta teori. Umumnya LKS yang dianalisis hanya menanyakan terkait konsep saja misalnya seperti pertumbuhan daun batang dan kotiledon tanpa mengaitkannya dengan prinsip ataupun teori. Konsep, prinsip dan teori dapat mendukung proses pencatatan data dan transformasi data karena pemahaman terkait konsep, prinsip dan teori membantu dan mengarahkan siswa untuk mengorganisasi data yang didapatkan sehingga data yang didapatkan dapat membentuk suatu klaim pengetahuan (Wahidah, 2018). Indikator keempat yaitu perekaman dan transformasi data. Hampir seluruhnya mencapai skor 2 yaitu kegiatan pencatatan dapat diidentifikasi tetapi tidak konsisten dengan pertanyaan atau kegiatan utama. Seluruh LKS sudah ada arahan agar siswa mencatat data yang diperoleh tetapi tidak didukung oleh pertanyaan utama. 


\section{Rekonstruksi Kegiatan Praktikum Pertumbuhan dan Perkembangan pada Tumbuhan}

Berdasarkan hasil analisis DKL dari berbagai sumber dan kurikulum, ditemukan bahwa sebagian besar DKL masih terdapat banyak kekurangan baik pada aspek relevansi, kompetensi, praktikal dan konstruksi pengetahuan. Di samping itu, setelah dilakukan analisis DKL hasil uji cobapun hasilnya mendukung hasil analisis sebelumnya yaitu masih terdapat beberapa kesalahan terutama pada bahan yang digunakan dan langkah kerja, yang dimana keduanya merupakan faktor penentu dalam kesuksesan pemahaman konsep, prinsip dan teori bagi peserta didik. Oleh karena itu, perlu dilakukan rekonstruksi atau perbaikan DKL agar peserta didik mendapatkan pemahaman yang sesuai dengan tujuan praktikum dan tuntutan kurikulum. Berdasarkan hal tersebut, berikut pemaparan alternatif rekonstruksi DKL struktur darah yang diharapkan mampu mengatasi kekurangan/kesalahan pada beberapa DKL sebelumnya.

\section{Kompetensi Dasar}

3.1 Menjelaskan pengaruh faktor internal dan faktor eksternal terhadap pertumbuhan dan perkembangan makhluk hidup.

4.1 Menyusun laporan hasil percobaan tentang pengaruh faktor eksternal terhadap proses pertumbuhan dan perkembangan tanaman.

\section{Tujuan}

1. Untuk mengetahui perkembangan dan pertumbuhan pada perkecambahan.

2. Untuk mengetahui faktor-faktor yang mempengaruhi pertumbuhan dan perkembangan pada perkecambahan.

\section{Dasar Teori}

Tumbuh dan berkembang merupakan salah satu ciri makhluk hidup. Pertumbuhan dan perkembangan berjalan seiring. Pertumbuhan dinyatakan sebagai pertambahan volume yang tidak dapat balik. Proses pertumbuhan berlangsung selama fase pembesaran sel, dan sebagian kecil dalam fase pembelahan dan pendewasaan sel. Pertumbuhan dapat diukur dan dinyatakan secara kuantitatif. Perkembangan adalah terspesialisasinya sel-sel menuju ke struktur dan fungsi tertentu. Perkembangan tidak dapat dinyatakan dengan ukuran, tetapi dinyatakan dengan perubahan bentuk dan tingkat kedewasaan. Perkecambahan adalah munculnya plantula (tanaman kecil) dari dalam biji terjadi proses fisika (imbibisi), penyerapan air oleh biji menjadi lunak. Pada perkecambahan dibedakan menjadi 2, yaitu:

1. Epigeal (perkecambahan di atas tanah)

2. Hipogeal (perkecambahan di bawah tanah)

Faktor-faktor yang mempengaruhi pertumbuhan dan perkembangan pada tumbuhan:

1. Oksigen

2. Cahaya

3. Suhu

4. Dan air

\section{Alat dan Bahan}

Bahan tanaman: 10 biji kacang hijau yang bermutu baik.

Alat-alat: Gelas aqua berukuran $240 \mathrm{ml}$, penggaris $30 \mathrm{~cm}$, dan kapas, pingset.

\section{Cara kerja}

Perkembangan pada perkecambahan kacang hijau yaitu:

1. Siapkan dua buah gelas aqua ukuran $240 \mathrm{ml}$ dengan keadaan yang bersih. 
2. Pilihlah 10 biji kacang hijau yang bermutu bagus pada segenggam biji kacang hijau.

3. Masukkan dengan pingset 1 lembar kapas ke dalam gelas aqua ukuran $240 \mathrm{ml}$ dalam keadaan basah.

4. Masukkan masing-masing 5 biji kacang hijau pada gelas aqua ukuran $240 \mathrm{ml}$ yang berisi kapas dengan perlakuan yang berbeda.

5. Tempelkan label pada masing-masing gelas aqua ukuran $240 \mathrm{ml}$, pada label 1 dengan perlakuan di ruangan tertutup, pada label 2 dengan perlakuan di ruangan terbuka yang sudah terisi biji kacang hijau.

6. Amati perkembangan pertumbuhan pada biji kacang hijau selama \pm 2 minggu pada jam 07.00 pagi.

Tabel Pengamatan Perkecambahan Biji Kacang Hijau

Tabel 1. Perlakuan di ruangan tertutup

\begin{tabular}{|c|c|c|c|c|c|c|}
\hline \multirow{2}{*}{ Hari ke } & \multicolumn{5}{|c|}{ Jumlah Biji } & \multirow{2}{*}{ Keterangan } \\
\cline { 2 - 7 } & 1 & 2 & 3 & 4 & 5 & \\
\hline 1. & & & & & & \\
\hline 2. & & & & & & \\
\hline 3. & & & & & & \\
\hline 4. & & & & & & \\
\hline 5. & & & & & & \\
\hline 6. & & & & & & \\
\hline
\end{tabular}

Tabel 2. pengamatan (perlakuan di ruangan terbuka)

\begin{tabular}{|c|c|c|c|c|c|c|}
\hline \multirow{2}{*}{ HARI KE } & \multicolumn{5}{|c|}{ Jumlah Biji } & \multirow{2}{*}{ Keterangan } \\
\cline { 2 - 6 } & 1 & 2 & 3 & 4 & 5 & \\
\hline 1 & & & & & & \\
\hline 2 & & & & & & \\
\hline 3 & & & & & & \\
\hline 4 & & & & & & \\
\hline 5 & & & & & & \\
\hline 6 & & & & & & \\
\hline
\end{tabular}

Diskusikan:

1. Adakah pertambahan pertumbuhan pada biji kacang hijau? Jelaskan!

2. faktor-faktor apa saja yang mempengaruhi pertumbuhan dan perkembangan pada perkecambahan.

3. Adakah perbedaan pola pertumbuhan pada perlakuan yang di ruangan terbuka dengan di ruangan tertutup? Kalau ada jelaskan! 


\section{SIMPULAN}

Berdasarkan hasil analisis dan uji coba Langkah kerja terhadap salah satu DKL mengenai materi pertumbuhan dan perkembangan tumbuhan ditemukan beberapa kekurangan. Kekurangan tersebut didapatkann pada langkah kerja, alat dan bahan yang digunakan serta penyajian data pengamatan Sebagian besar DKL sudah memiliki komponen relevansi, kompetensi, praktikal dan konstruksi pengetahuan Diagram Vee, Namun masih banyak pula DKL yang belum sesuai. Rekontruksi DKL menghasilkan alternatif DKL pertumbuhan dan perkembangan tumbuhan dengan mempertimbangkan dan melengkapi kekurangan hasil analisis dari DKL yang sudah di analisis. Rekontruksi DKL ini diharapkan mampu mengkontruksi pengetahuan peserta didik dengan baik melalui kegiatan praktikum yang dilaukan serta mampu mendapatkan keterampilan $4 \mathrm{C}$ atau keterampilan abad 21 yang dibutuhkan saat ini

\section{RUJUKAN}

Abraham, I., \& Millar, R. (2008). Does Practical Work Really Work? A Study of the Effectveness of Prcatical Work as a Teaching and Learning Method in School Science. International Journal of Science Education.

Fadzil, H. ., \& Saat, R. . (2020). Exploring Secondary School Biology Teachers' Competency in Practical Work. Jurnal Pendidikan IPA Indonesia, 9(1).

Hamidah, A., Sari, E. N., \& Budianingsih, R. S. (2014). Persepsi Siswa tentang Kegiatan Praktikum Biologi di Laboratorium SMA Negeri se-Kota Jambi. Jurnal Sainmatika, 8(1).

Millar, R. (2004). The role of practical work in the teaching and learning of science. National Academi of Science.

Muhali. (2018). Arah Pengembangan Pendidikan Masa Kini Menurut Perspektif Revolusi Industri 4.0. Seminar Nasional Lembaga Penelitian Dan Pendidikan (LPP) Mandala. Novak, J.., \& Gowin, D.. (1985). Learning How to Learn. Cambridge: Cambridge University Press

Sunarno, W. (2018). Pembelajaran IPA di Era Revolusi Industri 4.0. Madiun

Turner, F., Brownhill, S., \& Wilson, E. (2017). The transfer of content knowledge in a cascade model of professional development. Teacher Development, 21(2), 175-191

Turner, F., Brownhill, S., \& Wilson, E. (2017). The transfer of content knowledge in a cascade model of professional development. Teacher Development, 21(2), 175-191.

Wahidah, N. S., Supriatno, B., \& Kusumastuti, M. N. (2018). Analisis Struktur dan Kemunculan Tingkat Kognitif pada Desain Kegiatan Laboratorium Materi Fotosintesis. Indonesian Journal of Biology Education, 1(2). Winkel, W. . (1996). Psikologi Pengajaran. Jakarta: Erlangga. 